\title{
Leading innovation through employees participation: plural leadership in employee-driven innovation practices
}

\author{
Authors: \\ Nicole Flocco ${ }^{1}$, Filomena Canterino ${ }^{1}$, Raffaella Cagliano ${ }^{1}$ \\ ${ }^{1}$ School of Management, Politecnico di Milano, Italy \\ Paper published in "Leadership".
}

Please cite as: Flocco N, Canterino F, Cagliano R. (2021) Leading innovation through employees' participation: Plural leadership in employee-driven innovation practices. Leadership, in press, https://doi.org/10.1177/1742715020987928 


\title{
Leading innovation through employees participation:
}

\section{plural leadership in employee-driven innovation practices}

\begin{abstract}
Plural leadership has gained a lot of attention, challenging traditional individualistic leadership models and moving the focus to the dynamic and collective nature of leadership. This leadership paradigm seems particularly relevant in situations where plurality is involved to cope with complexity and uncertainty: a valid example is the context of innovation. In this study, we explore how plural leadership works in the context of employee-driven innovation (EDI), since these initiatives can provide interesting insights about the interactions between formal and informal leaders. Our empirical analysis supports the idea that EDI involves plural leadership. We identified some similarities with two of the streams theorized by Denis, Langley and Sergi (2012) in "Leadership in the Plural", namely "sharing leadership in teams" and "producing leadership through interaction." Through multiple case studies, it was possible to extend those streams and to deepen our understanding of the relationship between formal and informal leaders. We conceptualized two leadership roles (i.e., process leadership and content leadership), which enable plural leadership to meet the competing demand of exploration and exploitation, and we revealed elements that help explain why and when leadership is shared between multiple individuals.
\end{abstract}

\section{Keywords}

Plural leadership, employee-driven innovation, plural leadership roles, formal leaders, informal leaders 


\section{Introduction}

Plural leadership has gained a lot of attention in recent years, challenging traditional individualistic, "heroic" leadership models, and moving the focus to the "dynamic, collective, situated and dialectical nature" of leadership (Denis, Langley \& Rouleau, 2010). Plural leadership is defined as "a collective phenomenon that is distributed or shared among different people, potentially fluid, and constructed in interaction" (Denis, Langley \& Sergi, 2012: 2).

This leadership paradigm seems especially relevant for innovation, as complexity and uncertainty make it unrealistic for a single individual to successfully perform all the leading functions needed in the innovation process (Sun et al. 2016; Hunter, Cushenbery \& Jayne, 2017). Recent research adopting a positivist perspective has demonstrated the positive impact of plural forms of leadership on individual and team innovativeness, considering a number of antecedents, moderating and mediating variables (Mei \& Wang, 2013; Lee et al. 2015; Sun et al. 2016; Hu et al. 2017).

However, we still have a limited understanding of how multiple leaders interact in the innovation process and participate in the production of innovative ideas. Indeed, having a plurality of leaders introduces new questions about the coexistence of what has been called "formal" and "informal" leadership. Formal leadership, sometimes labelled vertical or hierarchical leadership (Denis, Langley \& Sergi, 2012), focuses on individuals whose leadership claims are tied to rank or position (Pearce and Conger, 2003) sanctioning their ability to "define and determine organizational direction" (Collinson, 2017: 276). Informal leadership in contrast relies on the idea that any organization member may exert influence and become a de facto leader, through their ability to mobilize others to action independently of the trappings of formal designation or hierarchy (Gronn, 2002).

The role of formalization and power has always brought up some issues in leadership literature. Examining leadership research from a critical perspective, Learmonth and Morrell (2017) suggest that the terms 'leader' and 'follower' are increasingly replacing 'manager' and 
'worker' as the routine way to frame hierarchy within organizations. It may be true that "informed by the recent popularity of distributed leadership, managers have been encouraged and trained to see themselves as leaders" (Collinson, 2017: 276). However, a plural leadership perspective, at least in the way we frame it, does not assume a predetermined attribution of leadership and followership to certain positions (i.e. manager and workers). Rather it invites us to consider leadership and followership as emergent phenomena, influenced in part by formal designations, but also potentially spontaneous as some people propose courses of action, and others assent (or not) to their proposals (DeRue and Ashford, 2010). In other words, the notion of plural leadership introduces the possibility that leadership may be exerted by managers or by people in non-managerial roles according to a range of different configurations (Gronn, 2002). However, very few studies have empirically explored how formal (designated) and informal (emergent) leaders interact.

The aim of this research is to investigate the role of formal and informal leaders within the innovation process and to understand how plural leadership emerges and evolves over time in the context of innovation. In particular, we focus on a specific innovation setting: employeedriven innovation (EDI).

EDI has been defined as "the generation and implementation of new ideas, products, and processes, including the everyday remaking of jobs and organizational practices, originating from employee interaction" (Høyrup, 2012: p.8). These practices are characterized by high involvement, autonomy, activism and flexibility, and they require the contribution of ordinary employees, at all levels of the organization, beyond the boundaries of their primary job responsibilities (Høyrup, 2010). Proponents of this idea have suggested that it requires "new leadership paradigms" (Hamel, 2006) as managers involved in EDI need to cooperate and share responsibilities for innovation with ordinary employees. This innovation setting thus seems particularly suitable for studying the interactive dynamics between formal and informal leaders. 
The rest of the paper is organized as follows: in section 2 we introduce the literature background, presenting the concepts of plural leadership and EDI, in order to situate our findings. In section 3 we present our methodology and cases, while in section 4 we introduce our findings that will be later discussed in section 5 .

\section{Literature Background}

\subsection{Plural Leadership}

Different terminologies to describe forms of plural leadership have been conceptualized over the years, such as "distributed leadership" (Gronn, 2002), "shared leadership" (Pearce and Conger, 2003), and "collective leadership" (Friedrich et al. 2009). Indeed, this area of research frequently shows overlap in definitions and the use of the same words interchangeably. At the same time, the field also reveals some ontological and epistemological divides as well.

A seminal contribution which provides clarity concerning these conceptualizations of plural leadership comes from Denis, Langley, \& Sergi (2012), who highlight four streams of scholarship on leadership in the plural. In the first stream, which is mainly connected with "shared leadership" studies, plural leadership can be associated with conceptions of democracy, empowerment, and participation among members of a team who mutually lead each other ("sharing leadership in teams"). In the second stream, which includes works under the label “collective leadership", plural leadership refers to two, three, or more people at the top-level who jointly work together as co-leaders of others outside the group ("pooling leadership at the top of organizations"). In the third stream, which is mostly associated with the term "distributed leadership", plural leadership appears as a chained relay process moving between people from one hierarchical level to another, across intra-organizational and inter-organizational boundaries ("spreading leadership across boundaries over time"). Finally, leadership can be seen as a human social construction, decentred from individuals and attributed to activities and processes rather than persons ("producing leadership through interaction"). In this last stream, 
it is the direction emerging from interaction among people that constitutes leadership rather than the agency of any particular individual or collection of individuals.

A growing number of studies are exploring the relationship between plural leadership and innovation, since innovation represents a typical process where "a plurality of leaders is needed because no single individual alone could conceivably bridge the sources of influence, expertise, and legitimacy needed to move a complex social system forward constructively" (Denis, Langley, \& Sergi 2012: 62).

The majority of studies on plural leadership and innovation have explored the stream of "sharing leadership in teams" with a variance approach. For example, interesting results have been produced on the mediating and moderating variables involved in the relationship between shared leadership and team creativity. We know that shared leadership positively affects team creativity through knowledge-sharing (Lee et al., 2015) and constructive controversy (Sun et al. 2016). Moreover, it reinforces the U-shaped (curvilinear) relationship between team creativity and task conflict (Hu et al., 2017). Shared leadership is also positively related to individual creativity via knowledge sharing, and task interdependence moderates this relationship (Gu et al., 2018). Other studies have discussed the impact of shared leadership on innovation performance. For example, Mei and Wang (2013) examined the mediating effect of knowledge sharing, and the moderating role of task complexity. Hoch (2013) further considered shared leadership as a mediating variable between vertical leadership, team member integrity and team innovative behaviour (Hoch, 2013).

The connection between shared leadership and innovation thus seems fairly strong. However, we question the assumption of shared goals and empowerment that underpins much of this literature, as well as the dichotomization between formal and informal leadership inherent to this stream. Frequently this literature opposes shared leadership to vertical leadership, presenting influence sharing as a choice which is under the control of formal 
appointed leaders, who empower the team to use shared leadership in place of vertical leadership.

Whether or not and how roles are shared between formal and informal leaders is an empirical question which we intend to examine in this research. For this reason, we decided to use the umbrella definition of "plural leadership" to explore leadership in EDI. Through our case study analysis, we ask how the people involved in EDI construct leadership and whether the approaches they adopt are coherent with 'shared' or other plural forms of leadership described by Denis et al. (2012).

\subsection{Formal and informal leadership}

The relationship between formal and informal leadership represents a complex issue in the leadership literature. At one extreme, as described by Denis et al. (2012: 60), in some studies, "the notion of formal organization in which different individuals hold different degrees of authority or resource-based influence almost disappears" and leadership seems to exist in an empty “powerlessness" space (Fletcher, 2004). In other studies, the sharing of leadership roles appears to be seen as a "gift of formal leaders", undermining the spontaneous, emergent and possibly conflicting nature of this process.

Leadership research seems particularly prone to dichotomization (Collinson, 2019), which refers to the tendency to exaggerate conceptual differences between concepts whilst neglecting similarities, overlaps and interrelations. A first dichotomy in this literature is the distinction between managers and leaders. Some authors criticize the tendency to call managers leaders (Learmonth and Morrell, 2017). Other studies instead admit a possible overlap between management and leadership. For example, Collinson (2017: 276) refuses the definition of management and leadership "as an either/or situation (i.e. that you are either a manager or a leader but cannot be both, sometimes at the same time)".

According to plural leadership literature, leadership should not be confused with formal authority. Nevertheless, people with some kind of formal power, such as external sponsors, 
coaches, team advisors, project managers, can exert leadership (Hoch, 2013) and be recognized as doing so by others. It would therefore be interesting to understand empirically when and why managers are considered to be leaders by the people they work with. Conceptually, in this paper, the notion of formal or vertical/hierarchical leadership refers specifically to this situation.

The second dichotomy refers to the distinction between leaders and followers. Learmonth and Morrell (2017) criticize the tendency to replace the word 'worker' with 'follower', accusing critical leadership scholars of automatically depicting workers as followers. Collinson (2017) responds that this argument falls into the mainstream conception of leaders as those who mobilize followers and followers as those who freely and participatively follow. While critical leadership studies recognize that followers do not have to blindly obey to leaders, they also recognize that followers may have a range of possible means of resisting leaders' attempts to exert power.

This debate however seems to assume that employees are always subordinated, and that they have "limited capacity to influence the direction of their organizations" (Collinson, 2017: 280), even though they may manifest resistance. It does not consider the possibility of thinking about employees as leaders. On this topic plural leadership takes a step forward: leaders with hierarchical authority can of course influence the direction of an organization, but so can employees without formal authority, as we explore in this paper. Indeed, sometimes, plural leadership "may actually emerge as a response to structural constraints, as those with limited structural power develop leadership capacities within the process of getting organized to oppose authority or domination" (Denis, Langley \& Sergi, 2012: 61). Alternatively, employees may also lead in domains where power, authority, and expertise are in any case widely dispersed and a multitude of individuals will inevitably exert influence, as happens in EDI.

There are, thus, a multiplicity of actors inside and across organizations who can exert leadership, not only formal leaders. According to plural leadership perspectives, managers and employees can potentially both lead and follow in different moments. Leadership and 
followership can be considered states or conditions that can be occupied at various times by different people: "Individuals can move in and out of leader-follower relations, subtly and continuously, as they engage in the co-constructing collective leadership" (Empson \& Alvehus, 2019: 19).

Conceptually we have clarified so far what we mean in this paper by formal and informal leadership. The last dichotomy we would like to address is precisely that between these two forms of leadership. Formal and informal leadership are usually treated as a dualism, i.e., opposites where we either have vertical leadership or shared leadership (Contractor et al., 2012). Yet, informal leadership does not exist independently of formal leadership in most organizations. Indeed, Denis et al. (2012: 61) suggest that there is a need to "consider more systematically how the formal structuring of leadership roles and their spontaneous emergence interact dynamically over time."

In general, several frameworks have conceptualized vertical leadership as an antecedent of shared leadership, assuming that formal leaders can exhibit behaviours that empower employees and encourage shared leadership (Cox et al. 2003, Pearce, 2004). These studies implicitly promote the idea that informal leadership is granted by vertical leaders and it arises in absence of designated leadership roles, while in many cases structured and emergent leadership coexist as a "de facto condition of organizational life" (Denis, Langley, \& Sergi, 2012). In this paper, we will explore situations where both formal and informal leaders interact, in different leadership configurations, to produce innovation. We consider EDI an ideal setting to achieve this goal, as further explained in the following section.

\subsection{Employee-driven innovation and Leadership}

According to Kesting and Ulhøi (2010: p.66) "employee-driven innovation (EDI) refers to the generation and implementation of significant new ideas, products, and processes originating from a single employee or the joint efforts of two or more employees who are not assigned to this task". EDI indeed, focuses on the innovative potential of ordinary employees, at all levels 
of the organization, and not just those employees working in R\&D functions (Høyrup et al. 2018).

The concept of EDI includes a variety of different processes, triggered by autonomous or induced strategic behaviours (Mirabeau \& Maguire, 2014): (i) processes that are not intentional or planned, but happen serendipitously, (ii) processes carried out by employees "behind the scenes", and therefore not visible to management during a certain period of time, (iii) processes that are initiated by employees and immediately supported and coordinated by management, and (iv) processes that are initiated by managers who develop practices to involve employees in innovation (Høyrup et al. 2018). Managers can therefore be more or less involved in EDI and might have a key role in producing innovation with ordinary employees.

Scholars have studied EDI showing the complexity and implications of these practices, and particularly focusing on employees and organizational perspectives. Some scholars have explored the behaviours of employees involved in these activities. For example, Lempiälä et al. (2018) highlight how two teams within a similar structural setting perceive their ability to engage in EDI in a different way: as development workers or innovation activists. This perception affects employees' ability to make use of EDI. Kurz et al. (2018) analyse the innovative behaviour of ordinary employees compared to employees from whom highly innovative behaviours are expected, showing that an appropriate job design that stresses autonomy and innovativeness as job requirements influences employees' innovative behaviour.

Other authors explored some organizational practices that may facilitate EDI: Sorensen et al. (2018) identify specific mechanisms that are key to implementing EDI in a governmental client organization (i.e. organizational trust, innovation safety, organizational practices, cultural settings, and the recognition and rewards structure that motivate employees). Lotz (2018) shows how three routines (a form of communities of practice, a cookbook, and a set of governance procedures to support continual improvements) trigger moments of recursive learning and EDI in a multinational corporation. 
Few studies have provided some hints about leadership in EDI: we know that EDI challenges traditional management principles based on hierarchy and control, and instead relies on openness and transparency, which requires managers to let go of controlling and monitoring (Amundsen et al. 2014), be open in terms of hierarchical structure and authority, and acknowledge ordinary employees as partners (Smith et al. 2012).

We argue that plural leadership can be essential to implementing EDI. Employees from different organizational levels may arise as informal leaders in these initiatives, and we think this setting can provide interesting insight into how multiple leaders, both formal and informal, interact within the innovation process. As a consequence, in this study we address the following research question: RQ. How do formal and informal leadership work in the context of EDI?

\section{Methodology}

\subsection{Case Selection}

Multiple case studies were conducted to explore our research question. We identified eight companies that were implementing EDI, by looking at their websites and recent news. Although the benefits of EDI are well described in the literature, these initiatives are not extensively diffused in practice. Indeed, EDI reflects an ambition to democratize innovation, and it is not clear that many organizations wish to achieve this goal. EDI requires job autonomy, decentralized decision making, and collaboration, some assumptions that might challenge traditional management principles. Thus, relatively few organizations are trying to implement EDI, while many others consider innovation to be the responsibility of specific R\&D functions and managers (Kesting and Ulhøi, 2010).

We identified companies that were implementing EDI and contacted them by email, explaining our research project. Five organizations were available to participate in the study (Table 1). Within these companies we analysed different EDI practices: (i) initiatives where employees worked in a leaderless team but had to cooperate with an external manager (i.e. Polo), (ii) initiatives where the person who proposed the innovative idea (the innovator) was considered 
the formal leader of the group (i.e. Colombo, Nobile, Monzino), (iii) and initiatives where there was no innovator, but an appointed team-leader was responsible for the group (i.e. Vespucci). We therefore explored different degrees of formality in our cases, since both hierarchical leaders (managers), and designated leaders (innovators or team leaders) were involved in the initiatives investigated. Assignments of formal leadership roles were directly reported by the people involved in the innovation process, not by the authors of this paper. Through data analysis we later explore how those in appointed formal leadership roles actually exerted their leadership and what this meant in the context of employee driven innovation.

Table 1. Case description

\begin{tabular}{|c|c|c|c|c|c|}
\hline Company & Sector & $\begin{array}{c}\text { EDI } \\
\text { Practice }\end{array}$ & Interviewees & $\begin{array}{c}\text { Number } \\
\text { of } \\
\text { interviews }\end{array}$ & $\begin{array}{c}\text { Type of } \\
\text { innovation }\end{array}$ \\
\hline Colombo & Conglomerate & $\begin{array}{l}\text { 15\% Time } \\
\text { Culture: } \\
\text { Appointed } \\
\text { innovator }\end{array}$ & $\begin{array}{l}\text { - } \quad \text { Alessandro, Senior } \\
\text { Manager } \\
\text { - } \quad \text { Cristina, Manager } \\
\text { - } \quad \text { Marco, Employee }\end{array}$ & 3 & $\begin{array}{l}\text { Product and } \\
\text { technology } \\
\text { innovation }\end{array}$ \\
\hline Vespucci & IT & $\begin{array}{l}\text { Country } \\
\text { Innovation } \\
\text { Team: } \\
\text { Appointed } \\
\text { team leader } \\
\text { in the team }\end{array}$ & $\begin{array}{l}\text { - } \text { Marco, Executive } \\
\text { Partner } \\
\text { - } \quad \text { Roberto, Senior } \\
\text { Manager } \\
\text { - } 3 \text { Employees (Nadia, } \\
\text { Carlo, Simone) }\end{array}$ & 5 & $\begin{array}{l}\text { Product and } \\
\text { process } \\
\text { innovation }\end{array}$ \\
\hline Polo & Energy & $\begin{array}{l}\text { Innovation } \\
\text { Map \& } \\
\text { Innovation } \\
\text { Lab: } \\
\text { Leaderless } \\
\text { team, } \\
\text { supported by } \\
\text { external } \\
\text { managers }\end{array}$ & $\begin{array}{l}\text { - Carlotta, Manager } \\
\text { - } 9 \text { Employees } \\
\text { (Davide, Umberto, } \\
\text { Massimo, Renata, } \\
\text { Pietro, Francesco, } \\
\text { Gabriele, Marilde, } \\
\text { Franco) }\end{array}$ & 10 & $\begin{array}{l}\text { Process } \\
\text { innovation }\end{array}$ \\
\hline Nobile & Consultancy & $\begin{array}{l}\text { Hackathons: } \\
\text { Appointed } \\
\text { innovator } \\
\text { and } \\
\text { managers in } \\
\text { the team }\end{array}$ & $\begin{array}{l}\text { - } 2 \text { Executive Partners } \\
\text { (Giampiero, } \\
\text { Giacomo) } \\
\text { - Lucia, Senior } \\
\text { Manager } \\
\text { - Enrico, Manager } \\
\text { - } 2 \text { Employees (Marta, } \\
\text { Emanuele) }\end{array}$ & 6 & $\begin{array}{l}\text { Product and } \\
\text { process } \\
\text { innovation }\end{array}$ \\
\hline Monzino & Consultancy & $\begin{array}{l}\text { Innovation } \\
\text { challenges } \\
\& \\
\text { Hackathon: }\end{array}$ & $\begin{array}{l}\text { 4 Senior Manager } \\
\text { (Gabriele, Claudio, } \\
\text { Alessio, Alessandro) } \\
\text { 6 Employees } \\
\text { (Francesca, Filippo, }\end{array}$ & 10 & $\begin{array}{c}\text { Product and } \\
\text { process } \\
\text { innovation }\end{array}$ \\
\hline
\end{tabular}




\begin{tabular}{|l|l|c|c|c|c|}
\hline & $\begin{array}{c}\text { Appointed } \\
\text { innovator } \\
\text { and } \\
\text { managers in } \\
\text { the team }\end{array}$ & $\begin{array}{c}\text { Carlo, Luca, Andrea, } \\
\text { Stefano) }\end{array}$ & & & \\
& & & & \\
\hline
\end{tabular}

At Colombo, we explored a permanent EDI initiative called " $15 \%$ Time Culture": employees propose to their managers an innovative idea they personally identify (a new product or a new technology) and managers give them $15 \%$ of free time to work on the idea, with the goal of patenting and developing an innovative product or technology.

At Vespucci, we explored an EDI initiative called "Country Innovation Team": during the year top managers identify different areas that require innovation (connected to the company process and products) and they put together teams of selected employees from different business units, guided by a team leader and supported by an executive sponsor, with the assignment to develop a detailed innovative proposal.

At Polo we explored an EDI initiative divided into two parts: "The Innovation Map" and "The Innovation Lab". Managers ideated a gamification event where all company employees were involved in proposing innovative ideas. Then managers created different teams of employees with an assigned innovation topic. Employees worked on their own in a leaderless team in order to produce and implement an innovative proposal.

At Nobile, we explored a permanent EDI initiative in the form of hackathons directed to employees, who post their ideas in the company social network to answer a call on a specific topic. The most appreciated ideas are selected and the teams, guided by an innovator and made up of employees and managers, join a 48-hour weekend event where they work on and develop their innovative idea.

At Monzino, we explored an EDI initiative divided into two parts: four innovation challenges and a hackathon. At first, employees were asked to post their ideas in an internal crowdsourcing platform in order to answer four different innovation challenges. Several teams were formed that included both employees and managers and, guided by an innovator, they 
worked on different steps to refine their innovative idea. Nine of the projects generated during the innovation challenges were selected at the end to be further developed during a 48-hour hackathon.

\subsection{Data Collection and Analysis}

Data collection was performed following a semi-structured interview protocol. We conducted 34 interviews with informants from different hierarchical levels. We asked interviewees to provide their definition of leadership, to name leaders and describe their role in the EDI initiatives in which they were involved. Additional information about the practices explored were collected through internal documents and presentations.

We transcribed the data and one of the researchers in the team wrote a summary of each EDI initiative. Then, we performed several rounds of coding, looking at how respondents constructed leadership in the five cases. The codes shown in the findings section have been translated from the original language of the interviews.

Using an iterative process, we identified first order and second order codes, that were ultimately related to the four streams of plural leadership theorized by Denis, Langley, \& Sergi (2012). In our initial analysis, we identified a clear distinction between formal and informal leaders, and developed a description of leadership as dynamic and distributed. In further analysing our data, we examined why and when leadership is shared, and how leadership roles were distributed between formal and informal leaders. We finally engaged in an interpretative analysis of our codes, considering the different EDI practices and plural leadership configurations found in each case.

\section{Findings}

Our findings support the assumption that EDI involves plural leadership. Our data show how plural leadership works in these initiatives, highlighting a distribution of leadership roles 
between formal and informal leaders, and informing on why and when leadership rotates between multiple individuals.

\subsection{Formal and Informal Leadership}

Our empirical analysis shows that participants identify multiple leaders as contributing to EDI; this multiplicity is connected not only to the number of leaders, but also to their nature. Interviewees explain that two different kinds of leadership take place during EDI: participants spontaneously make a distinction between formal leaders, who are appointed leaders, with a recognisable role (i.e. a manager, a supervisor, a team leader), and informal leaders who emerge in specific situations, without a predefined role:

«There are leaders defined as leaders: we have a scale of job descriptions and job grades and from certain level on you are a manager or supervisor, so these are formal leaders. However, it is becoming more and more relevant to define situational leaders, and temporary leaders» (Alessandro - senior manager - Colombo case)

«It is clear that there are also situations in which leaders arise because of their behaviour. They have the ability to pull people even though they may not be labelled as leaders, because their role does not necessarily give them this possibility, but a leadership behaviour is what allows the person to be followed» (Massimo - employee - Polo case)

Our informants underline another difference between leadership about process (i.e. leadership connected to the organization and advancement of the innovation process), and leadership about content (i.e. leadership connected to contribution and competencies):

«In this type of work, there are typically two types of leadership, a project management leadership because this activity must have its timing, its situation, its way to advance in order to produce a result, that is the project with its proposal. Plus, another leadership linked more to functional skills, to domain competencies » (Roberto - senior manager - Vespucci case) 
These leadership roles (i.e. process and content leadership) can be covered both by formal and informal leaders. Thus, this distinction is based on what leaders do, not on the level of formalization of the leadership role. Formal and informal leaders can lead in both process and content domains.

As anticipated in the methodology section, we explored several EDI practices which present different leadership configurations. Multiple leaders were mentioned in all cases, despite the presence of a formal appointed leader in the team. Informal leadership was found not only in teams with no designated leader but also in initiatives where a predefined individual was supposed to lead the team. Indeed, when our interviewees were asked to identify a leader in their team, if there was a formal leader (i.e. team leader, innovator), employees named her/him as someone that guided the team, but they also specified that leadership was shared between the team members:

«There is the formal leader, but inside the team itself, of course, when you work, there is a silent leadership, because you can tell people how to do stuff in a better way, with a common goal, to do the best project possible. It was really natural in the team» (Emanuele - employee - Nobile case)

The presence of an appointed formal leader in the group does not prevent the spontaneous emergence of informal leadership. However, while interviewees easily assess formal leadership, informal leadership was described as a "fluid" process (as reported also at beginning of the section 4.3), not always attributed to specific individuals:

«I think leadership dynamics in the group are very interesting, because the innovator is the one who really leads, because obviously it's his idea and we are talking about knowledge, but it is also very levelled» (Andrea - employee - Monzino case)

While reporting assignments of leadership role, a common answer was that all team members showed leadership behaviours, but interviewees were not always able to name informal leaders:

«In my team I saw leadership behaviours practically in all the participants» (Simone - 
senior manager - Vespucci case)

«Regarding this dynamic of leadership in our group, I don't think that there has been a dominant figure, perhaps in alternate phases, we have passed the "baton" based on the phase of the project» (Renata - employee - Polo case)

«If I had to name a leader I could not tell you who s/he was. The formal figure of the innovator in this case was covered by Giulia. Pietro and I were theoretically contributors, but there were times when the work was carried forward more by Pietro, more by me, or more by Giulia (...) leadership in that sense was dictated by the nature of the work» (Luca - employee - Monzino case)

Leadership in EDI appears influenced by formal designations, but it is also spontaneous. If we consider the four streams of plural leadership introduced by Denis, Langley, \& Sergi (2012), we can see that our empirics resonate with two of those streams: namely "sharing leadership in teams" and "producing leadership through interaction". However, our findings also question some elements of those streams.

The "shared leadership" stream usually opposes emergent leadership to vertical leadership. Instead in our empirical data, we see that these two forms of leadership can happen simultaneously - they can coexist. Leadership can be shared even in a team guided by an appointed formal leader. There are some cases more coherent with the shared leadership tradition. For example, in Polo, the manager is just an external support and employees are "empowered" to pursue innovation on their own. However, in other cases, like Nobile and Monzino, informal leadership emerges even in the presence of appointed leaders, as described in the codes. In general, informal leadership is not granted by formal leaders, but spontaneously arises.

Our data have some affinity also with the stream "producing leadership through interaction". Informants describe leadership as a social construction or a collective achievement, and frequently they are not able to name leaders. However, there are some 
extensions to this stream as well. The inability to name leaders is limited to informal leadership, while people with a formal role are always recognised as leaders by the informants. This result leads us to two considerations. First, it is easier of course to appoint people with a formal role (i.e. managers, innovators) as leaders. Because of their position, they are supposed to lead others. However, informants attributed leadership to these individuals not only because of their position, but because they manifested some leadership behaviours (see section 4.2). Second, formal leaders generally took on a process leadership role (see section 4.2). It is easier to observe process leadership while it is complicated to grasp content leadership and pinpoint it to specific individuals. Several people can contribute to shape contents in different moments, even with small interactions. Informal leadership is usually associated with content leadership, and this may explain why it is difficult to describe. The stream of "producing leadership through interaction" conceptualizes leadership as decentred from individuals and attributed to activities and processes. Our informants describe content leadership as a dynamic process, however to some extent they still believe leadership is embodied by individuals. Even if they are not able to say who, they prefer to answer that they are "all" leaders.

Finally, there is no connection with the stream "pooling leadership at the top of organizations" because in EDI we did not find two, three, or more people at the top-level who jointly work together as co-leaders of others outside the group. Nor did we find a chained relay process moving between people from one hierarchical level to another, as conceptualized by the stream "spreading leadership across boundaries over time". These two streams do not appear to be applicable to the context of EDI as we observed it, but of course they can be useful to analyse other contexts and other leadership configurations.

\subsection{Process vs. Content Leadership}

With reference to multiple leadership roles, we find a quite homogeneous distribution between formal and informal leaders. Interviewees provide their personal definition of leadership, which involves multiple behaviours: leaders are able to organize and guide the team to a common 
goal; leaders are doers, active contributors, and mentors; they are able to listen, solve problems and provide support and information. Interviewees also describe the distribution of leadership roles in their teams, and we discovered some common patterns in the cases.

When a formal leader is present in the team s/he is usually the one who organizes the work and guides the team to the final goal (process leadership):

«The team leader definitely gave indications, the team leader and the executive sponsor told us "we want to get this result and we try to organize ourselves in this way"» (Carlo - employee - Vespucci case)

However, in a leaderless team, this role can be covered also by informal leaders:

«Informal leaders that emerge in a natural way, and that emerge at the time of need, were obviously important both in the choice of ideas (...) and especially when we need to come to a synthesis. Because we all have beautiful ideas. How to put them into practice is a different thing and it always takes someone who can make a synthesis of ideas, or activities or things to do. In fact, we need at some point someone to emerge and control the situation from an operational point of view (...) it was necessary at one point to have someone who directed the operations, and it was not necessarily always the same person» (Umberto - employee - Polo case)

Formal leaders are usually the ones who lead the process. However, in their absence, informal leaders can also cover this role. Formal leaders also cover a networking role, they represent an interface between the team and top management, and they favour commitment:

«One thing mostly done by formal leaders was to bring the commitment of various people to participate in these initiatives...the formal leaders had more work to do because they took care to pull people inside, to collaborate with everyone, to put them together and act as a glue for all the activities.... We had to present our idea to the 
managing director, and the two leadership figures [team leader and executive sponsor] take care of that» (Carlo - employee - Vespucci case)

Finally, formal leaders are responsible for providing support during critical moments:

«There were also some critical moments, but I think it's normal, because it's a team that basically is created for that event. So you don't know other people, and this can happen, There are some, let's say, contrasts between group members. Let's say different opinions on how to proceed, but in that case, it is always the formal leader that tries to mediate the conflicts» (Emanuele - employee - Nobile case)

On the other side informal leaders are presented as doers, as proactive leaders, the ones that contribute to the project with their knowledge, ideas and passion (content leadership):

«I see the leaders, you are the leader if you basically have the knowledge of the project, you have enthusiasm in the project, I mean, if you are very interested in the project and you can teach other people to do it, the directions to take, also without authority, but they follow you because they feel you are right.» (Emanuele - employee - Nobile case) Informal leaders can also cover networking roles, predominantly to acquire external knowledge and information:

«At one point it was also the team that became responsible to expand its borders a little, there was a core team and then we asked questions to the people around who could be the experts for a certain area and so on» (Carlo - employee - Vespucci case)

Therefore, while the networking role is usually performed by both formal and informal leaders, the two roles of leading process and leading content benefit from a division between formal and informal leaders. We claim that the reason behind this distribution is the intrinsic tension between these activities. The data show a tension between process leadership (organizing and advancing the process) and content leadership (contributing with knowledge, ideas and passion): 
«Visionary leaders are relevant maybe on the innovation characteristic, they are really high, normally they are down on prioritizing and executing because they need someone else to do this for them. Very few people are able to be really visionary, but then normally they are not so good in execution» (Alessandro - senior manager - Colombo case)

«We had within the group a senior manager who, in my opinion, has made a very important contribution towards better structuring our presentation. I think senior managers, considering their experience and know-how, are the people who can refine the solution. At an innovative level, the solution can be easily developed even better by people who have less pre-existing conceptual structures. The more you are virgin, the easier it is for you to have lateral thinking, it's easier to develop from scratch for a person with lower seniority like me.» (Andrea - employee - Monzino case)

There is, therefore, a tension between structure and innovation: being a leader who can direct and organize the team (process leadership) is different from being the leader who can inspire, bring knowledge and innovation to the team (content leadership). Interviewees tend to divide these roles between formal and informal leaders. However, this division is not mandatory. Informal leaders can also lead the process in the absence of formal leaders, while formal leaders can be innovators and therefore can also lead contents.

The distribution of leadership roles among individuals is influenced by the presence of formal leaders in the innovation team. When there is an appointed formal leader in the team, the distribution of leadership roles is pre-determined: the formal leader is automatically invested with the role of leading process. On the other side, in leaderless teams, multiple leaders can emerge and distribute roles spontaneously.

As anticipated in section 4.1, the insights on content and process leadership extend the stream of "producing leadership through interaction". Leading content indeed is described as something collectively achieved. 


\subsection{Leadership as a Dynamic Process}

In all the cases, leadership was described as dynamic process, rotating in a "liquid", "fluid" and "natural" way:

«Leadership has been dynamic. Everyone has a different personality, so everyone tends to show his/her presence in a team in a certain way. However, leadership is dynamic. It has not been pre-imposed or imposed by anyone specific» (Francesco - employee Polo case)

«In the same team, you will have people coming from different units and leading different phases, and you have to be really fluid in that» (Lucia - senior manager Nobile case)

«You switch on as a leader because there is a project involving you, and you are the best; then it will be someone else after 2-3 months to start something else and you will follow and be part of the team. This is a kind of liquid leadership» (Alessandro - senior manager - Colombo case)

These words stress the idea that informal leadership is not granted by formal leaders. Rather it spontaneously emerges. Moreover, the codes show people can move in and out from leader and follower roles, through time.

We also understand that leadership in EDI rotates between team members for several reasons. First, because of the knowledge required in the project:

«I feel that I lead others for some parts because I had some knowledge about chatbots, I worked on this topic before in other projects, so from this point of view, yes, I lead others» (Emanuele - employee - Nobile case)

Team members also share leadership dynamically because of the workload. In EDI employees need to balance ordinary workloads with the time dedicated to innovation, and that is a reason to share leadership with other team members:

«It's a sort of shifting leadership, passing from person to person depending on both the know-how and the time we have. Sometimes, I have spare time from job duties, sometimes other colleagues have more spare time and we just share these possibilities and leadership. It depends even on this aspect» (Davide - employee - Polo case)

Moreover, leadership rotates also because of people's personalities: 
«Everyone has taken, in a collaborative way, the responsibility of guiding others in a certain situation. This depends in part on competences, which are relevant, but I believe that depends more on personality» (Carlo - employee - Vespucci case)

Finally, leadership rotates because of the needs of each project phase, not only in terms of knowledge, as we have seen, but also in terms of the attitude required in different stages:

«In the creative phase everyone was trying to bring ideas. In that part, I think I was the leader more than others, because I tried to impose my idea, using the skill of convincing people, giving details and a vision. The idea was not so clever but the direction to follow was what we needed in that phase. In the second phase, there was the need for someone who was more structured and organized, so we were putting everything together and we needed to organise every idea, every aspect and we have someone in finance who was very precise and organized who could do that, and in that phase she was the leader, absolutely» (Francesco - employee- Polo case)

Beside why leadership is dynamic, our empirical analysis also shed more light on when leadership roles rotate among team members. In the Polo case, where no formal leader is appointed within the team, leadership is described as shared from the beginning:

«It was a project without any role...being a heterogeneous team immediately helped us divide the work according to skills... so it was quite natural that each of us explored the field in which s/he had more expertise. During idea generation, obviously sometimes certain people emerged above the others, because they are those with a more creative attitude. Others instead had a more practical mental habit that keeps you grounded. Maybe you had a brilliant idea but it is not feasible, so there was a series of leadership dynamics in that sense. However, each one brought her/his own contribution because of her/his attitude and the skills s/he had» (Umberto - employee - Polo case)

In cases where a formal leader (a team leader or an innovator) was appointed in the team, s/he was followed at the beginning but then leadership gradually became shared:

«There was more of an initial planning activity, in the moments of meetings and during the most creative phases, but then the concept of team leader increasingly vanished, we are basically now a very close team of four people who work without a true hierarchical structure» (Simone - senior manager - Vespucci case) 
«At the beginning, there was a little more vertical leadership, not in terms of hierarchy but in terms of knowledge of the idea. Of course, once you get more or less all the same level of knowledge and you can compare and everyone can say his/her opinion; then leadership becomes more and more flat, until there are even two or three people together with the innovator who carry on this idea. For example, we had the chance to talk to a CEO about this idea and I went there, not the innovator» (Andrea - employee-Monzino case)

The presence of formal leaders in the innovation team influences not only leadership roles but also leadership dynamics, by affecting the moment in which informal leaders emerge. We also understand that specific EDI characteristics might determine the potential for plural leadership. For example, the need to rotate leadership can be dictated by the workload of people. This is a specific characteristic of EDI, since in these practices, employees from different organizational units and different hierarchical levels need to devote part of their time to innovation, without forgetting their ordinary job responsibilities.

\section{Discussion}

This research provides significant insights into recent debates about plural leadership and innovation. To the best of our knowledge, this is one of the first studies exploring leadership in EDI. Our empirical analysis supports the idea that EDI involves plural leadership. We identified some similarities with two of the streams theorized by Denis, Langley, \& Sergi (2012): namely "sharing leadership in teams" and "producing leadership through interaction". The other two perspectives "pooling leadership" and "spreading leadership", tend to "retain the notion that some are leaders and some are followers" (Denis, Langley, \& Sergi, 2012), and were not observed in the context of our EDI initiatives.

Leadership has been described as dynamically shared between multiple individuals who cover multiple leadership roles. This is coherent with studies reporting the positive influence of shared leadership on innovation (Hoch, 2013; Lee et al. 2015; Sun et al. 2016; Hu et al. 
2017), especially in the context of teams. However, some elements from our study are not completely in line with the shared leadership perspective.

First, our work questions the dichotomy between formal and informal leadership implicitly promoted by the aforementioned literature. Frequently that literature opposes shared leadership to vertical leadership, presenting influence/sharing as a choice under the control of formal appointed leaders, who empower the team to use shared leadership in place of vertical leadership. In contrast, some studies seem to argue that power is absent when leadership is shared, and that this form of leadership is power neutral and associated with "powerlessness" (Fletcher, 2004).

In our cases, participants reported the copresence of designated and emergent leaders and stressed the fact that leadership is "spontaneously" and "naturally" shared. Shared leadership studies have usually treated formal and informal leadership as two separate entities (Contractor et al., 2012: 999). We find that formal and informal leadership should not be treated as two extremes of a scale, rather they often coexist in the same process, and leadership flows naturally between multiple people (with formal authority and not) for different reasons associated with knowledge, workload, personality and because of the needs of each process phase.

Second, in the shared leadership literature there is an implicit assumption that leadership is characterized "either by a formal separation of roles and responsibilities or by intuitive mutual adjustment" (Empson, 2020). In our cases we show that it is possible to have both designated and spontaneous attribution of leadership roles. There is a sort of pre-determined division of roles since formal leaders are usually invested in the role of leading the process (organizing and advancing the work), while informal leaders usually lead content (contributing with their knowledge and ideas). However, the data also show that this division of roles is not mandatory and can be adjusted according to the situation. Formal leaders can also lead content, and informal leaders can lead process. Intuitive mutual adjustment can occur because of the 
process itself (i.e. people can spontaneously re-adjust leadership roles when the workload is challenging, or a spontaneous redistribution of leadership roles can occur because of the needs of specific process stages), or because of the leadership configuration considered (i.e. in teams without a formal appointed leader, there is an intuitive distribution of leadership roles since the beginning).

We also understand that dividing leading process and leading content roles between formal and informal leaders can help solve a paradox between organization and innovation. Our interviewees underline a tension between being a leader who can organize the team to reach certain goals and being a leader who can inspire and bring innovation to the team. This tension is somehow expressed also in other research projects. According to some scholars, the ability to create new knowledge and to innovate does indeed stand in a fundamental tension with common aims of organizing such as routinization, efficiency, standardization and complexity reduction (DeFillippi, Grabher, \& Jones 2007, Ortmann \& Sydow, 2018).

Dividing process and content leadership roles may help solving this tension, and enable the joint pursuit of efficiency in project organization and innovation. This result is coherent with some contribution in the literature; for example, Kakar (2017) found that vertical leadership has a higher positive impact on team efficiency, shared leadership has a higher positive impact on team innovation, while balanced shared and vertical leadership optimally impacts team effectiveness. Hunter, Cushenbery \& Jayne (2017) proposed the addition of a second leader with a clear role of either exploration or exploitation as a means to share the workload and successfully lead for innovation. However, as already anticipated, this division of roles is useful but not mandatory. The data illustrate situations where people with no formal power were leading the process, or formal leaders were leading content. In EDI it is possible to find a mix of structured and spontaneous divisions of the leadership roles. The degree of role sharedness varies depending on the situation.

Finally, we also noticed similarities with the stream "producing leadership through 
interaction". The data show that while formal leadership is easily recognised, informal leadership is usually described as a fluid process, not necessarily attributed to specific individuals. Formal leaders are easily appointed, also because they influence the direction of the process by planning, organizing, providing support. Therefore, it is easier to assess process leadership. In contrast, informal leadership is usually associated with the role of leading content, which seems something collectively achieved and more difficult to map. Therefore, informal leadership is not usually attributed to specific individuals but to the whole team.

This observation can extend the stream of "producing leadership through interaction" (Denis et al., 2012). In fact, the distinction between process and content leadership that has emerged from our empirics helps clarify that it may be mainly content leadership that is "produced through interaction". Content leadership is achieved thanks to multiple individuals. Informants are not able to say exactly how this happened, and they prefer to say they "all" contributed. The processual approach proposed by the "producing leadership" stream can help further understand how content leadership works. Moreover, it can also help verify whether process leadership is a linear process (mainly managed by formal leaders) as described by our informants, or whether it is to some extent negotiated and constructed in interaction as well.

Finally, in contrast with the assumptions of the "producing leadership" stream, informants still describe leadership as a property of individuals, not just as a process. A peoplecentred view of leadership persists for them, at least at a subconscious level (they cannot name informal leaders, but they say they "all" contributed). A common critique of the "producing leadership" stream is the risk of diluting the distinctiveness of leadership if it is conceptualized as an organizing process, decentred from individuals. "When studied as a mundane activity to which every actor can contribute, leadership may easily disappear or become difficult to distinguish from other phenomena, such as decision-making, problem-solving or simply teamworking" (Denis, Langley, \& Sergi, 2012). Our empirical data suggest that even if content leadership is interactively constructed, there is still the need to consider how multiple actors 
contribute to the creation of a shared direction. Again, a process approach can be useful to really grasp how content leadership works.

\section{Conclusion}

Through this research, it was possible to shed more light on how plural leadership works in the context of EDI, and to deepen our understanding of the relationship between formal and informal leaders.

We found the presence of both formal and informal leaders in EDI and a division of leadership roles between the two. Formal leaders usually lead the process and support the team especially in critical moments, and informal leaders usually lead content. Both formal and informal leaders cover networking leadership roles. This division of roles between formal and informal leaders is useful but not mandatory and can be adjusted according to the situation.

We also revealed elements that help explain why and when leadership is shared between multiple leaders. Leadership in EDI is described as a dynamic process, rotating because of knowledge, workload, personality and because of the needs of each process phase. When a formal leader is present within a team during an EDI initiative, s/he usually leads at the beginning and gradually leadership become shared between different members; when employees work in a team without a formal leader, leadership is shared from the beginning.

This study contributes to the literature on plural leadership and innovation and has implications for both scholars and practitioners. In terms of scholarly implications, ours is one of the first studies that explores leadership in EDI, and we contribute to understanding how leadership works in this context. In particular, we highlight some of the practices that enable plural leadership to support innovation (i.e. dividing the roles of leading process and leading content to meet the competing demand of exploration and exploitation). We also add to two of the perspectives on plural leadership theorized by Denis, Langley, \& Sergi (2012): "sharing leadership in teams" and "producing leadership through interaction". 
From a practitioner perspective, by exploring how leadership works in EDI, it was possible to understand the relevance of employees as informal leaders in these contexts: these findings may be useful to practitioners who want to structure EDI practices in their companies. Employees hold hidden potential for innovation: if managers are open to considering employees as leaders and to promoting a culture that fosters plural leadership, they may be able to achieve both efficiency in project organization and innovation.

Of course, this research is not without limitations. Our semi-structured interviews enabled us to understand how leadership is manifested in EDI; however, in order to better grasp how content leadership works and how leadership rotates over time between formal and informal leaders, future research might enrich our findings using an ethnographic approach or discourse analysis. Moreover, additional cases performed in other contexts might offer further insights into different configurations of plural leadership, exploring, for example, dyads of formal leaders, dyads of informal leaders, teams composed only by formal leaders, or interorganizational leadership interactions.

\section{References}

Amundsen O, Aasen TM, Gressgård LJ, Hansen K (2014). Preparing organizations for employee-driven open innovation. International Journal of Business Science and Applied Management 9(1): 24-35

Carson JB, \& Tesluk PE (2007). Leadership from within: A look at leadership roles in teams. In: 67th annual meeting of the Academy of Management, Philadelphia

Collinson D (2014) Dichotomies, dialectics and dilemmas: New directions for critical leadership studies. Leadership 10(1): 36-55

Collinson, D (2017). Critical leadership studies: A response to Learmonth and Morrell. Leadership, 13(3): 272-284 
Contractor NS, DeChurch LA, Carson J, Carter D, \& Keegan B (2012). The topology of collective leadership. Leadership Quarterly, 23: 994-1011

Cox JF, Pearce CL, \& Perry M (2003). Toward a model of shared leadership and distributed influence in the innovation process: How shared leadership can enhance new product development team dynamics and effectiveness. In CL Pearce \& JA Conger (Eds.), Shared leadership: Reframing the How's and Whys of leadership (pp. 48-68). Thousand Oaks, CA: SAGE.

DeFillippi R, Grabher G, \& Jones C (2007). Introduction to paradoxes of creativity: managerial and organizational challenges in the cultural economy. Journal of Organizational Behavior, 28 (5): $511-521$

Denis JL, Langley A, Rouleau L (2010). The practice of leadership in the messy world of organizations. Leadership, 6(1): 67-88

Denis JL, Langley A, Sergi V (2012). Leadership in the Plural. Academy of Management Annals 6(1): 211-283

DeRue, DS, \& Ashford, SJ (2010). Who will lead and who will follow? A social process of leadership identity construction in organizations. Academy of Management Review, 35(4), $627-647$.

Empson, L (2020). Ambiguous authority and hidden hierarchy: Collective leadership in an elite professional service firm. Leadership, 16(1), 62-86

Empson, L, \& Alvehus, J (2019). Collective Leadership Dynamics among Professional Peers: Co-constructing an unstable equilibrium. Organization Studies 1-23

Fletcher JK (2004). The paradox of postheroic leadership: An essay on gender, power, and transformational change. Leadership Quarterly, 15(5): 647-661 
Friedrich TL, Vessey WB, Schuelke MJ, Ruark GA, \& Mumford MD (2009). A framework for understanding collective leadership: The selective utilization of leader and team expertise within networks. The Leadership Quarterly, 20(6): 933-958

Gronn P (2002). Distributed leadership as a unit of analysis. The Leadership Quarterly, 13: $423-451$

Hamel G (2006). The why, what, and how of management innovation. Harvard Business Review, 84 (2), 72-84

Hiller NJ, Day DV, \& Vance RJ (2006). Collective enactment of leadership roles and team effectiveness: A field study. Leadership Quarterly, 17: 387-397

Høyrup S (2010). Employee-driven innovation and workplace learning: Basic concepts, approaches and themes. Transfer: European Review of Labour and Research 16(2): 143-154

Høyrup S (2012). Employee-driven innovation: a new phenomenon, concept and mode of Innovation. In: Høyrup, S. et al. (Eds.): Employee Driven Innovation. Palgrave Macmillan, New York.

Høyrup S, Redien-Collot R, \& Teglborg A (2018). Introduction to the Special Issue on: Employee-Driven Innovation. International Journal of Entrepreneurship and Innovation Management 22(4-5): 317-322

Hoch JE (2013). Shared leadership and innovation: The role of vertical leadership and employee integrity. Journal of Business and Psychology, 28(2): 159-174

Hu N, Chen Z, Gu J, Huang S, Liu H (2017). Conflict and creativity in inter-organizational teams: The moderating role of shared leadership. International Journal of Conflict Management, 28 (1): 74-102

Hunter ST, Cushenbery L, Fairchild J \& Boatman J (2012). Partnerships in leading for innovation: A dyadic model of collective leadership. Industrial and Organizational Psychology: 
Perspectives on Science and Practice, 5 (4): 424-428.

Hunter ST, Cushenbery LD, Jayne B (2017). Why dual leaders will drive innovation: Resolving the exploration and exploitation dilemma with a conservation of resources solution. Journal Organizatinal Behavior, 38 (8): 1183-1195

Kakar AK (2017). Investigating the Prevalence and Performance Correlates of Vertical Versus Shared Leadership in Emergent Software Development Teams, Information Systems Management, 34(2): 172-184

Kesting P, Ulhøi JP (2010). Employee-driven innovation: Extending the license to foster innovation. Management Decision 48(1): 65-84

Kurz V, Hüsig S, Dowling M (2018). What drives different employee types of innovative behaviour? Development and test of an integrative model of employee driven innovation in German firms. International Journal of Entrepreneurship and Innovation Management 22(4-5): $397-426$

Learmonth, M, \& Morrell, K (2017). Is critical leadership studies 'critical'? Leadership, 13(3), $257-271$.

Lee DS, Lee KC, Seo YW, Choi DY (2015). An analysis of shared leadership, diversity, and team creativity in an e-learning environment. Computers in Human Behavior, 42: 47-56

Lempiäla T, Yli-Kauhaluoma S, Näsänen J (2018). Similar structures, different interpretations: Perceived possibilities for employee-driven innovation in two teams within an industrial organization. International Journal of Entrepreneurship and Innovation Management 22(4-5): $362-380$

Lotz MM (2018). Organising routines and spaces for employee-driven innovation in global work arrangements. International Journal of Entrepreneurship and Innovation Management 22(4-5): $338-361$ 
Mei HY, Wang JP (2013). The impact of shared leadership on innovation performance. In: International Conference on Management Science and Engineering - Annual Conference Proceedings, 1385 -1390

Mirabeau L, \& Maguire S (2014). From autonomous strategic behavior to emergent strategy. Strategic Management Journal, 35: 1202-1229

Murphy SE, Ensher EA (2008). A qualitative analysis of charismatic leadership in creative teams: The case of television directors. Leadership Quarterly, 19(3): 335-352

Ortmann G, \& Sydow J (2018). Dancing in chains: Creative practices in/of organizations. Organization Studies, 39(7): 899-921

Pearce CL (2004). The future of leadership: Combining vertical and shared leadership to transform knowledge work. Academy of Management Executive, 18(1): 47-57

Pearce CL, \& Conger JA (2003). Shared leadership: Reframing the hows and whys of leadership. Thousand Oaks, CA: Sage

Smith P, Ulhøi JP, Kesting P (2012). Mapping key antecedents of employee-driven innovations. International Journal of Human Resources Development and Management 12(3): 224-236

Sorensen H, Ussing LF, Wandahl S, Christensen RM (2018). Key mechanisms for employeedriven innovation in governmental client organisations. International Journal of Entrepreneurship and Innovation Management 22(4-5): 427-450

Sun, X, Jie Y, Wang Y, Xue G \& Liu Y (2016). Shared Leadership Improves Team Novelty: The Mechanism and Its Boundary Condition. Frontiers in Psychology, 7: 1664-1078

Yin RK (2003). Case Study Research: Design and Methods. Thousand Oaks, CA: Sage

Yukl, G. (2012). Effective leadership behavior: What we know and what questions need more attention. Academy of Management Perspectives, 26(4): 66-85. 